\title{
Coping of Cancer Patients During and After Radiotherapy - a Follow-Up of 2 Years
}

\author{
S. Sehlen ${ }^{a} \quad$ R. Song ${ }^{a} \quad$ H. Fahmüller ${ }^{a} \quad$ P. Herschbach ${ }^{b} \quad$ M. Lenk ${ }^{a} \quad$ H. Hollenhorst ${ }^{a}$ \\ B. Schymura ${ }^{a} \quad$ U. Aydemirc E. Dühmke ${ }^{a}$ \\ a Department of Radiotherapy and Radiooncology, Klinikum Großhadern, Ludwig Maximilians University, \\ ${ }^{\mathrm{b}}$ Institute and Polyclinic for Psychosomatic Medicine, Psychotherapy and Medical Psychology, Technical University, \\ c Institute for Biometry and Epidemiology, Klinikum Großhadern, Ludwig Maximilians University, Munich, Germany
}

\section{Key Words}

Coping - FKV · Freiburg Questionnaire Coping with Disease ·

Radiotherapy · Longitudinal investigation

\section{Summary}

Aim: We wanted to understand coping strategies specific to different phases up to two years after radiotherapy, to identify patients who are at higher risk of mood disturbances and to characterise the association between coping strategies and psychosocial adaptation. Patients and Methods: From 1997 to 2001, 2,169 patients with different diagnoses were screened (27.8\% refused to participate). Data of 276 patients from the beginning of radiotherapy (ti1) and 5 follow-up investigations (ti6/2 years) could be analysed. With the FKV (Freiburg Questionnaire Coping with Disease) cancer-specific coping aspects were assessed. The association between coping styles and psychosocial adaptation was evaluated using the Questionnaire on Stress in Cancer Patients (OSC) and the questionnaire on Functional Assessment of Cancer Treatment (FACT-G). Results: 'Active problem-orientated' coping and 'distractions' are the most important coping strategies. Only 'active problemorientated' and 'depressive' coping showed a significant decrease. We observed higher means on the scales of the FKV in women. Marital status (single, married, divorced/widowed) had a significant influence on active problem-orientated coping and spirituality. Age, children, education, T/M status and curative/palliative intention of treatment had no influence on coping styles. Breast cancer patients and lymphoma patients demonstrated the highest use of coping strategies after radiotherapy with a significant decrease of 'active problem-orientated coping'. Depressive coping and minimizing importance at ti1 were associated with high psychosocial distress and low quality of life ( $\mathrm{OoL}$ ) at ti6. Conclusion: The correlation of coping mechanisms at the beginning of radiotherapy with low QoL and high psychosocial stress at 2 years could help to identify patients at risk for low psychosocial adaptation. Psychooncologically trained teams of physicians would best correspond to this profile of needs and would contribute significantly to an ameliorated adaptation of patients to cancer which could lead to higher life satisfaction.
Schlüsselwörter

Krankheitsverarbeitung · FKV · Freiburger Fragebogen zur Krankheitsbewältigung · Strahlentherapie · Langzeitbeobachtung

\section{Zusammenfassung}

Ziel: Ziel war es, spezifische krankheitsverarbeitende Prozesse bis zu 2 Jahre nach Strahlentherapie aufzudecken, Patienten mit einem erhöhten Risiko von psychosozialen Störungen zu identifizieren und den Zusammenhang zwischen den Copingstrategien und der psychosozialen Krankheitsanpassung zu untersuchen. Patienten und Methode: Von 1997 bis 2001 wurden 2169 Patienten mit unterschiedlichen Diagnosen untersucht (27,8\% verweigerten die Teilnahme). Die Daten von 276 Patienten vom Beginn der Strahlentherapie (ti1) und 5 Followup Untersuchungen (ti6/2 Jahre) konnten ausgewertet werden. Mit dem FKV (Freiburger Fragebogen zur Krankheitsbewältigung) wurden krebsspezifische Aspekte der Krankheitsverarbeitung erhoben. Für die Untersuchung des Zusammenhangs zwischen Copingstrategien und psychosozialer Anpassung wurde der Fragebogen zur Belastung von Krebskranken (FBK) sowie der Functional Assessment of Cancer Treatment (FACTG) eingesetzt. Ergebnisse: Die Copingmechanismen «aktiv problemorientiert" und "depressiv" spielten die größte Rolle und zeigten eine signifikanten Abfall. Frauen wiesen einen höheren FKV-Wert in allen Skalen auf. Familienstand hatte einen signifikanten Einfluss auf problemorientiertes Coping und Religiosität. Alter, Kinder, Ausbildung, T/M-Status oder kurative/palliative Therapie waren ohne Einfluss auf die Copingstrategie. Mammakarzinom-Patientinnen machten am häufigsten $\mathrm{Ge}$ brauch von Copingstrategien mit einem signifikanten Abfall des "aktiv-problemorientierten" Copings, wie auch Patienten mit Lymphomen. "Depressives Coping" und "Bagatellisierung und Wunschdenken" zu Beginn gingen einher mit hoher psychosozialer Belastung und geringer Lebensqualität nach 2 Jahren. Zusammenfassung: Durch die Identifizierung von Patienten, die nach zwei Jahren eine schlechte psychosoziale Adaptation zeigen, bereits zu Beginn der Strahlentherapie können psychoonkologisch geschulte Ärzte zu einer besseren Krankheitsverarbeitung von Krebspatienten und damit einer höheren Lebenszufriedenheit beitragen.

\begin{tabular}{ll}
\hline KARGER & @ 2003 S. Karger GmbH, Freiburg \\
Fax +497614520714 & Accessible online at: \\
$\begin{array}{l}\text { E-mail Information@Karger.de } \\
\text { www.karger.com }\end{array}$ & www.karger.com/onk
\end{tabular}

Dr. Susanne Sehlen

Strahlentherapie und Radioonkologie, LMU München Klinikum Großhadern

Marchioninistr. 15, D-81377 München

Tel. +49 89 7095-6767, Fax -4523

E-mail susanne.sehlen@helios.med.uni-muenchen.de 


\section{Background}

Different personal and interpersonal challenges accompany the first years after a cancer diagnosis. In this context the concepts of coping and mental adjustment have been studied intensively in psychosocial research. Mental adjustment has been defined by Greer et al. [1] as cognitive and behavioural responses to life-threatening events which may also include emotional reactions that mediate coping. Coping has been defined as cognitive and behavioural efforts, mediating relationships between a stressful situation and physiological and psychological adaptation [2].

Coping strategies have been found to be directly related to health status. The emphasis on anxiety and depression as psychiatric symptoms reveals only part of the story about how people cope with disease. Another quite different aspect concerns psychological well-being and the coping processes that support it [3]. Therefore coping could be conceptualized as a process somewhat changeable over time and dependent on the type of situation [2]. Although coping strategies are not inherently adaptive or maladaptive, previous research has consistently found disengagement strategies (i.e., behavioural and cognitive avoidance) to be associated with greater emotional distress, whereas active coping strategies (i.e., acceptance and planning) contribute to greater psychosocial well-being and more positive affect [4]. The most frequently employed scale for coping with disease used in Germany is the Freiburg Questionnaire Coping with Disease (FKV) by Muthny [5]. This questionnaire assesses a broad spectrum of coping strategies in chronic disease (e.g. cardiac disease, cancer, illnesses necessitating dialysis, multiple sclerosis). It is suitable for process measuring and economical application and has good acceptance [6, 7].

Special radiotherapy-related anxiety and distress could be the treatment side-effects, the unpleasant ambience of the waiting room and disturbing experiences in the linear accelerator room [8]. At present, studies investigating the coping or the quality of life in tumour patients during radiotherapy are few $[9,10]$. In particular, longitudinal studies of coping in patients confronting cancer are rare [11].

The primary aim of this study was to improve our knowledge of the influence of medical and sociodemographic variables on coping strategies specific to different phases during and up to two years after radiotherapy. A second aim was to assess the influence of coping strategies on psychosocial distress and quality of life. This could facilitate the identification of patients who are at higher risk of developing a mood disturbance and show whether coping strategies directed toward active engagement with stressors are associated with more positive adaptation and whether strategies geared towards avoidance are related to greater distress in tumour patients.

\section{Patients and Methods}

The participating patients received questionnaires at 6 defined points of their treatment: at the beginning of radiotherapy (ti1), at the end of radiotherapy (ti2), 6 weeks (ti3), 6 months (ti4), 1 year (ti5) and 2 years (ti6) after the end of radiotherapy. The following instruments were used:

- Life situation (LS), a self developed instrument.

- Freiburg Questionnaire Coping with Disease (Freiburger Fragebogen zur Krankheitsbewältigung, FKV-LIS [5]). The FKV measures different coping strategies on the basis of 35 items on five subscales (active problem-orientated coping, distractions, spirituality, minimizing importance and depressive coping).

- Questionnaire on Stress in Cancer Patients (QSC) [12]. The QSC is a 38-item self-rating questionnaire widely used in Germany for measuring psychosocial distress in cancer patients. Participants rated items on 6 scales (pain, anxiety or psychological distress, information, physical efficiency, social behaviour, partnership and family).

- Functional Assessment of Cancer Treatment (FACT-G), version 3 [13]. The FACT-G is a 29-item self-rating questionnaire for measuring disease-specific aspects of QoL in tumour patients. It consists of 5 subscales (physical, social/family, emotional and functional well-being and the patient's relationship with doctors).

Important variables affecting coping with disease in patients during and after radiotherapy are the following: sociodemographic data such as marital status, education etc. were assessed by means of a self-developed situation-of-life questionnaire. The survey of clinical data was taken from medical data at the 3 prespecified times. The relationship between coping strategies and psychosocial adaptation in terms of psychosocial distress and quality of life was evaluated by computing scale correlations.

Between November 1997 and June 2001, 2,169 patients in the Department of Radiotherapy at Klinikum Großhadern of the Ludwig Maximilians University, Munich, were included in the study. They had to be at least 18 years old and had to be able to understand and to read German fluently as well as to have the mental and physical capacity to understand and complete the questionnaire. The questionnaires were handed to the patients before their first fraction was delivered. Patients were informed of the aims of the study and were then asked to give a written informed consent. They were also informed that participation in the study and their therapy were in no way linked. The second visit was at the end of radiotherapy. Since most patients had then left the clinic, further questionnaires (ti3-ti6) were mailed to patients with a stamped, addressed envelope enclosed. All questionnaires included a letter which repeated the main points of the study. If questionnaires were not returned a reminder was sent to the patient.

Physical state was assessed during the first interview using the Karnofsky performance scale (KPS): A value of 50 and above was necessary to meet the inclusion criteria. 1,050 patients did not return the first questionnaire (refusals 55.9\%, low KPS 16.1\%, management problems 5.3\%, language barriers $6.9 \%$, cognitive restrictions $5.3 \%$, death $7.4 \%$, other $3.1 \%$ ). 1,089 patients took part in the study (table 1 ). At ti2 another $3.2 \%$ refused to participate (ti3 2.5\%; ti4 1.4\%; ti5 0.8\%; ti6 0.8\%), $2.5 \%$ had died (ti3 $2.2 \%$; ti4 3.6\%; ti5 2.4\%; ti6 2.1\%). Further patients could not be assessed because they experienced a decrease in their KPS (ti2 1.3\%, ti3 0.7\%, ti4 $0.7 \%$, ti5 $0.3 \%$, ti6 $0.1 \%$ ) or for other reasons (ti2 $1.0 \%$; ti3 $0.1 \%$ ). Full data sets with data for ti1-ti6 were obtained from 276 patients.

The distribution of the sociodemographic and medical data of participants and non-participants have been tested with the chi-square test. The medical variables tumour status (T status, $\mathrm{p} \leq 0.001)$ and diagnosis $(\mathrm{p}<0.001)$ differed significantly between the two groups.

The data were analyzed using the statistical package SPSS ${ }^{\circledR}$ for Windows ${ }^{\circledR}$ version 11.0. Changes in the FKV scores were tested with ANOVA and with Student's t-test, respectively. 
Table 1. Medical and sociodemograpic data at ti1 (for patients who completed ti1 questionnaire, $\mathrm{n}=1089)$

\begin{tabular}{|c|c|c|}
\hline \multicolumn{3}{|l|}{ Age, years } \\
\hline Median & \multirow{2}{*}{\multicolumn{2}{|c|}{$19-89$}} \\
\hline \multirow[t]{2}{*}{ Range } & & \\
\hline & $\mathrm{n}$ & $\%$ \\
\hline$\leq 45$ & 181 & 16.6 \\
\hline $46-60$ & 383 & 35.2 \\
\hline$>60$ & 525 & 48.2 \\
\hline \multicolumn{3}{|l|}{ Sex } \\
\hline Female & 470 & 43.2 \\
\hline Male & 619 & 56.8 \\
\hline \multicolumn{3}{|c|}{ Karnofsky performance score } \\
\hline$\leq 80$ & 419 & 38.5 \\
\hline $90-100$ & 670 & 61.5 \\
\hline \multicolumn{3}{|l|}{ Primary tumour } \\
\hline Gastrointestinal & 214 & 19.7 \\
\hline Breast cancer & 178 & 16.3 \\
\hline Head and neck & 173 & 15.9 \\
\hline Systemical & 135 & 12.4 \\
\hline Urogenital & 129 & 11.8 \\
\hline Lung & 108 & 9.9 \\
\hline Brain & 61 & 5.6 \\
\hline Gynaecological & 42 & 3.9 \\
\hline Other & 49 & 4.5 \\
\hline \multicolumn{3}{|l|}{ T stage } \\
\hline $\begin{array}{l}\text { T1/2, WHO I/II, Ann } \\
\text { Arbor I/II }\end{array}$ & 445 & 48.6 \\
\hline $\begin{array}{l}\text { T3/4, WHO III/IV, } \\
\text { Ann Arbor III/IV }\end{array}$ & 471 & 51.4 \\
\hline \multicolumn{3}{|l|}{ Metastases } \\
\hline No & 879 & 80.9 \\
\hline Yes & 208 & 19.1 \\
\hline \multicolumn{3}{|l|}{ Marital status } \\
\hline Single & 130 & 12.0 \\
\hline Married & 752 & 69.2 \\
\hline Divorced/widowed & 204 & 18.8 \\
\hline \multicolumn{3}{|c|}{ Level of secondary education } \\
\hline None/low & 387 & 42.1 \\
\hline Medium & 246 & 26.7 \\
\hline High & 286 & 31.1 \\
\hline \multicolumn{3}{|l|}{ Hospitalisation } \\
\hline Outpatient & 433 & 40.1 \\
\hline Inpatient & 648 & 59.9 \\
\hline
\end{tabular}

\section{Results}

Scales on the Freiburg Questionnaire Coping with Disease (FKV-LIS [5])

The analysis of the self-assessment of coping strategies in patients showed that 'active problem-orientated coping' (ti1 3.46 , ti6 3.05) as well as 'distraction and self-valorisation' (ti1 2.99 , ti6 2.98) played the most important role. Next came 'spirituality and search for meaning' (ti1 2.54, ti6 2.51), while 'minimising importance' (ti1 2.10, ti6 2.07) and 'depressive coping' (ti1 1.93, ti6 1.81) were less important. As table 2 shows, only 'active problem-orientated coping' $(\mathrm{p}=0.001)$ showed a significant decrease in the course of investigation (ti1-ti6). 'Depressive coping' decreased from ti1 to ti5 and increased at ti6 $(\mathrm{p}=0.003)$.

\section{Influence of Sociodemographic Variables on Coping Gender}

While analyzing the importance of gender in different coping strategies, we could observe higher mean values for female patients on the scales of the FKV on nearly all dates of the investigation (ti1-ti6). Over the whole period of the evaluation, the coping strategies which were used more often by the female patient group than by male patients were 'spirituality and search for meaning', 'minimizing importance' and 'distractions'. In addition, less intensive coping with the disease, using 'active problem-orientated coping' at the start (ti1) as well as 2 years after therapy (ti6) could be observed in both female and male patients, with significant changes (female: ti1 3.48 (SD 0.85) to ti6 3.00 (SD 0.98), male: ti1 3.44 (SD 0.74) to ti6 3.08 (SD 1.07); p value of repeated measurements $\mathrm{p}<$ $0.001)$ during the investigation. A higher decrease in 'depressive coping' was observed in men (ti1 1.98 (SD 0.69) to 1.79 (SD 0.68)) in contrast to women (ti1 1.88 (SD 0.73) to ti6 1.83 (SD 0.79)), with significant changes from ti1 to ti6 $(\mathrm{p}=0.002)$. Age

In the following analysis, the influence of age on the different mechanisms of coping was investigated. For this purpose, the patients were divided into 3 subgroups: patients under 45 , patients between 45 and 60 , and patients over 60 years. It was especially the coping strategy 'active problem-orientated' which significantly decreased (age < 45 years 3.42 (SD 0.89) to 2.77 (SD 1.03); 45-60 years 3.55 (SD 0.71) to 3.22 (SD 0.99); > 60 years 3.41 (SD 0.86) to 3.04 (SD 1.03)) in importance over the whole period $(\mathrm{p}<0.001)$. The youngest age-group, especially, did not use 'active problem orientated' coping so frequently in the follow-up study, while the middle-aged patient group used this coping mechanism relatively often from ti1 to ti6. 'Depressive coping' revealed significant changes with a decrease in the follow-up of the study (age $<45$ years 1.97 (SD 0.72) to 1.78 (SD 0.77); 45-60 years 1.94 (SD 0.71) to 1.88 (SD 0.77); $>60$ years $1.91(\mathrm{SD} 0.71)$ to $1.78(\mathrm{SD} 0.70)(\mathrm{p}=0.002))$. No age level in the different groups showed a significant change during investigation. This was also observed on the scales, 'distractions', 'spirituality' and 'minimizing importance'.

Marital Status, Children, Level of Secondary Education

No statistically significant influence either of the level of secondary education (none/low, medium, high) or of patients' children on the processes of coping could be demonstrated. Marital status (single, married, divorced/widowed) had a significant influence on the course of 'active problem-orientated' coping $(p=0.05)$ as well as 'spirituality' $(p=0.015)$. Single patients, especially, showed a decreased use of the 'active problem-orientated' coping mechanism.

\section{Influence of Medical Data on Coping}

\section{T-Status, M-Status, Curative/Palliative Aim of Radiotherapy}

In this analysis the patient group was divided into two subgroups based on the tumour stage: patients with early tumour stages (Ann Arbor or WHO I and II; T1 and T2) and 
Table 2. Freiburg Questionnaire Coping with Disease (FKV-LIS; [5]) - scales in the course of evaluation

Table 3. Correlation coefficients between coping styles (FKV-LIS) at ti1 and psychosocial distress (QSC) and quality of life (FACT) at ti6

\begin{tabular}{lllllllll}
\hline \multirow{2}{*}{ Scale } & \multicolumn{9}{l}{ Mean score (SD) } & & & p value* \\
\cline { 2 - 6 } & ti1 & ti2 & ti3 & ti4 & ti5 & ti6 & \\
\hline Active problem-orientated & 3.46 & 3.38 & 3.28 & 3.18 & 3.02 & 3.04 & $<0.001$ \\
& $(0.80)$ & $(0.78)$ & $(0.89)$ & $(0.88)$ & $(0.94)$ & $(1.02)$ & \\
Distractions & 2.99 & 3.07 & 2.98 & 3.02 & 2.94 & 2.98 & n.s \\
Spirituality & $(0.91)$ & $(0.82)$ & $(0.89)$ & $(0.92)$ & $(0.94)$ & $(0.98)$ & \\
& 2.54 & 2.59 & 2.47 & 2.50 & 2.49 & 2.52 & n.s \\
Minimizing importance & $(0.78)$ & $(0.77)$ & $(0.72)$ & $(0.77)$ & $(0.80)$ & $(0.79)$ & \\
& 2.12 & 2.21 & 2.22 & 2.19 & 2.13 & 2.07 & n.s \\
Depressive coping & $(0.98)$ & $(0.93)$ & $(0.95)$ & $(0.93)$ & $(0.97)$ & $(0.89)$ & \\
& 1.93 & 1.84 & 1.80 & 1.78 & 1.73 & 1.81 & 0.003 \\
& $(0.71)$ & $(0.71)$ & $(0.67)$ & $(0.67)$ & $(0.72)$ & $(0.74)$ & \\
\hline
\end{tabular}

*Of repeated measurements.

$\mathrm{SD}=$ Standard deviation, $\mathrm{n} . \mathrm{s}=$ not significant .

\begin{tabular}{llllll}
\hline & \multicolumn{2}{l}{ FKV-LIS ti1 } & & & \\
\cline { 2 - 6 } & $\begin{array}{l}\text { active problem- distractions } \\
\text { oriented }\end{array}$ & spirituality & $\begin{array}{l}\text { minimizing } \\
\text { importance }\end{array}$ & $\begin{array}{l}\text { depressive } \\
\text { coping }\end{array}$ \\
\hline QSC total score ti6 & 0.085 & 0.166 & 0.140 & 0.351 & 0.367 \\
$\quad$ p value & $<0.001$ & 0.007 & 0.021 & $<0.001$ & $<0.001$ \\
FACT-G total score ti6 & 0.092 & -0.019 & 0.005 & -0.314 & -0.360 \\
p value & n.s & n.s & n.s & $<0.001$ & $<0.001$ \\
\hline
\end{tabular}

n.s $=$ Not significant. patients with advanced tumour stages (Ann Arbor or WHO III and IV; T3 and T4). The comparison of these two groups revealed no significant differences in the adaptation to the cancer disease.

Patients diagnosed with metastases (M1) showed no higher values on the coping scales over the entire period of the study (ti1-ti6). Patients with metastases or advanced stages of disease with no chance of cure were defined as palliative patients. The differences between the curative or palliative aim of radiotherapy had no effect on the coping strategies in the course of the investigation.

\section{Diagnosis}

Five subgroups based on the site of the tumour were investigated: breast cancer, head and neck, urogenital and gastrointestinal carcinoma as well as lymphoma. The data of the specific tumour group were analyzed compared to the data of other tumour groups in order to discover differences in coping strategies for the follow-up investigation and in the tumour groups at each point in time. At ti4 we saw significant differences in 'active problem-orientated coping', with the highest values in breast cancer and the lowest in urogenital tumours (3.5 and 2.9; $\mathrm{p}=0.049$ ), and in 'distractions' (systemic disease 3.2 and urogenital tumour 2.6; $\mathrm{p}=0.025$ ). At ti5 significant differences were recognized in the coping strategies, 'distrac- tions' (breast cancer 3.2 and urogenital tumours 2.5; $\mathrm{p}=0.019$ ) and 'spirituality' (breast cancer 2.8 and urogenital tumours $2.3 ; \mathrm{p}=0.038$ ). At ti6 significant differences were observed in the coping strategies, 'active problem-orientated coping' (breast cancer 3.4 and urogenital tumours $3.0 ; \mathrm{p}=0.010$ ) and 'distractions' (breast cancer 3.3 and urogenital tumours 2.7; $\mathrm{p}$ $=0.032$ ). Patients at ti1, ti 2 and ti3 showed no differences in the processes of coping in the 5 subgroups.

The patient subgroup with breast cancer and systemic tumours assigned to the strategy of 'active problem-orientated coping' had a significant decrease in the use of this mechanism ( $\mathrm{p}=$ 0.05 and $p=0.021$ ). Patients with head and neck cancer, gastrointestinal or urogenital carcinoma showed no differences in mechanisms of coping in the follow-up (fig. 1+2).

\section{Psychosocial Adaptation}

The relationship between coping styles, psychosocial distress and quality of life has been evaluated by computation of scale correlations. The results (table 3 ) show that depressive coping and minimizing importance at ti1 was associated with high psychosocial distress $(\mathrm{r}=0.367, \mathrm{p}<0.001$ and $\mathrm{r}=0.351 \mathrm{p}<$ $0.001)$ and low quality of life $(\mathrm{r}=-0,360, \mathrm{p}<0.001$ and $\mathrm{r}=$ $-0.314, \mathrm{p}<0.001)$ at ti6. 
Fig. 1. Depressive coping strategy (FKV scores; [5]) by disease $(\mathrm{p}=0.020)$.

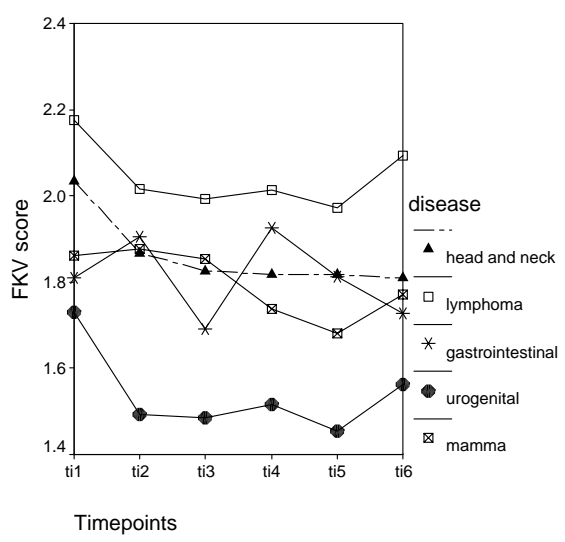

\section{Discussion}

In this prospective longitudinal study the processes of coping in cancer patients during and after radiotherapy was investigated by the well established Freiburg Questionnaire Coping with Disease (FKV-LIS) [5].

The analysis of the self-assessment questionnaires completed by patients showed that an active problem-orientated way of coping was of dominating importance followed by 'distractions'. 'Minimizing importance' as well as 'depressive coping' played a minor role. This pattern of coping strategies in cancer patients during radiotherapy can be found both in studies of tumour patients in radiooncology and in research on other chronically ill patients [7, 14-18], and can therefore be designated as being relatively unspecific for a particular disease.

The evaluation of the single item scales in the FKV revealed coping mechanisms involving high compliance with the medical system (especially 'follow the physician's advice', 'trust the physicians', 'seek further information about the disease and treatment') during and after radiotherapy. An explanation for this is that patients are in close contact with doctors during and immediately after therapy. With the increasing duration of the investigation - these active problem-orientated and also the depressive mechanisms showed a significant decrease in importance. In contrast, a study on coping with metastatic melanoma revealed that the use of active problemorientated coping increased [19]. Women frequently showed a much more intense reaction to the tumour disease than men. More positive outcomes for emotion-focused coping have already been demonstrated [20]. These gender differences correlate with higher values for depression in male patients, already described in the recent literature. However, some authors found no differences between men and women [21].

At the different dates of evaluation, various mechanisms for coping were used. The family background was investigated for the role played by partnership and children in the choice of coping strategies. These results were confirmed by studies attributing an essential role in the adaptation of the family of a patient to the disease [22]. The site of the tumour represented a factor of relatively minor importance in the strategies for
Fig. 2. Active problem-orientated coping strategy (FKV scores; [5]) by disease $(\mathrm{p}<0.001)$.

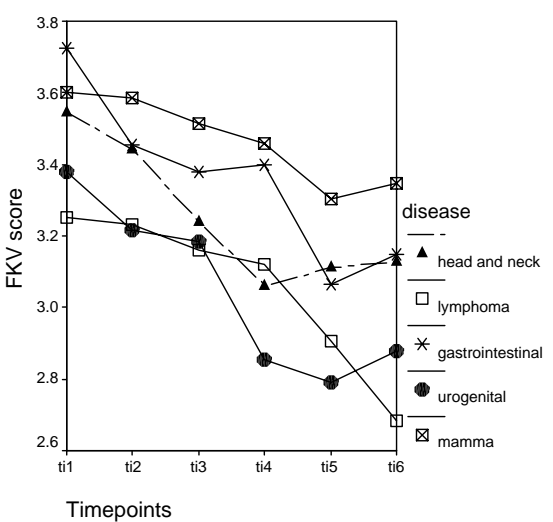

coping; only patients with breast cancer and systemic disease revealed significant changes to active problem-orientated coping during the course of the investigation. On the contrary, a considerably more 'active problem-orientated' and 'distractions' assimilation of the disease by patients with breast cancer in contrast to urogenital tumours was noticed 6 months after radiotherapy and later.

In contrast to other investigations, we could find no evidence for the effect of patients' children and the level of secondary education on the adaptation to the disease [23, 24]. Nevertheless, it already becomes apparent to what extent the preferred strategies of coping affect the degree of adaptation to the tumour disease: Patients' subjective life satisfaction with suitable coping mechanisms ameliorated steadily during the study, exceeding even the life satisfaction of another group of cancer patients [25]. Patients with unsuitable strategies for assimilating their disease, who at the beginning of treatment showed no differences from the above-mentioned group, subsequently revealed a distinctly deteriorated life satisfaction [26]. The investigations regarding depression and stress showed results which were similar in significance. As expected, the patients with negative coping strategies (for example 'minimizing importance' and 'depression') showed distinctly higher values of stress and depression as well as a generally lower satisfaction with life and a lower QoL after two years [27].

The more successful adaptation to disease with suitable coping strategies also became apparent in the degree of subjective psychological distress. Our group of patients complained of minor stresses and strains from the disease and treatment in contrast to patients with unsuitable coping strategies [28].

The more intensive subjective perception increases the objectively evaluated risk of side effects, depression and accompanying diseases [29]. A striking fact in these analyses, especially at the end of therapy as opposed to the beginning, was that the degree of the patient's adaptation to disease and quality of life diverged considerably depending on the preferred coping strategies. Consequently, the period of radiotherapy seemed to be of decisive importance for the degree of adaptation. Psychotherapeutic support for the adaptation to the disease could therefore result in an improved quality of life during the 
course of the disease in tumour patients undergoing radiotherapy.

The results of our study confirmed the already known, relatively slight oscillations in coping strategies during the course of the disease [30-32].

Thus the complex correlations between cause and effect in context of the assimilation of severe diseases could be analyzed more closely. Indications for the required psychotherapeutic support could be considered when the occasion arises. The importance of such care for tumour patients has already been described in several studies. This has resulted in an ameliorated emotional adaptation to disease as well as a diminution of moods like fear, anger or depression caused by the disease or by the treatment $[33,34]$. The long-term aim should be a highly specific, individually adapted programme of psychosocial support. Moreover, it should be borne in mind that patients who need psychotherapeutic help are often also most difficult to identify. However, the investigation of several background variables that could predict an insufficient adjustment to disease should be further investigated. The results of other studies $[35,36]$ are still to be put to the test as to their suitability for patients in radiotherapy. The influence of radiotherapeutic side-effects on coping strategies must be assessed by physicians and psychooncologists responsible for the patient [3]. Our study revealed the essential importance of the physician-patient relationship for the adjustment of tumour patients in radiotherapy to their disease. The need for further information from the physician and the opportunity to discuss psychological problems with the radiooncologist must be included [37, 38].

Of all patients who were approached $27.8 \%$ refused to participate. However, we had a heterogeneous sample of patients as well as a relatively positive selection of patients. This is was the result of the strict criteria for inclusion. The patients who most frequently refused to participate were those with a chronic, potentially life-threatening disease, such as pancreas carcinoma, head and neck cancer, bronchial carcinoma and brain tumour (as opposed to patients with breast cancer and lymphoma), or with high $\mathrm{T}$ status, often with metastases and therefore low Karnofsky index. This phenomenon has frequently been seen in QoL investigations and therefore should not diminish the validity of our results.

The correlation of 'depressive coping' and 'minimizing importance' at ti1 with low QoL and high pychosocial stress at ti6 could help to identify patients at risk for low psychosocial adaptation. A psychooncologically trained team of physicians in radiotherapeutic clinics would best correspond to this profile of needs and would contribute significantly to an ameliorated adaptation of patients to their disease which could lead to higher life satisfaction.

\section{Acknowledgement}

We thank Mrs. R. FitzGibbon for editorial assistance.

\section{References}

1 Greer S, Moorey S, Watson M: Patient adjustment to cancer: the Mental Adjustment to Cancer (MAC) scale vs clinical ratings. J Psychosom Res 1989:33:373-377.

2 Lazarus JT, Folkman S: Coping and adaption; in: Gentry WD (ed): Handbook of Behavioral Medicine. New York, Guilford, 1984, p 10.

3 Folkman S, Greer S: Promoting psychological wellbeing in the face of serious illness: When theory, research and practice inform each other. Psychooncology 2000;9:11-19.

4 Carver CS, Pozo C, Harris SD Noriega V, Scheier MF, Robinson DS, Ketcham AS, Moffat FL Jr., Clark KC: How coping mediates the effect of optimism on distress: A study of women with early stage breast cancer. J Pers Soc Psychol 1993;65: 375-390.

5 Muthny FA: Freiburger Fragebogen zur Krankheitsverarbeitung, Testmanual. Weinheim, Beltz, 1989.

6 Muthny FA: References for evaluation scales in quality assurance in rehabilitation. Assessment of coping processes with the Freiburger Questionnaire of Illness Coping. Rehabilitation (Stuttg) 1996;35: IX-XVI.

7 Muthny FA, Bechtel M, Spatete M: Laienätiologien und Krankheitsverarbeitung bei schweren körperlichen Erkrankungen: Eine empirische Vergleichsstudie mit Herzinfarkt-, Krebs-, Dialyse- und MS-Patientinnen. Psychother Psychosom Med Psychol 1992;42:41-53.
8 Schlömer U: Psychologische Unterstützung in der Strahlentherapie. Wien, Springer, 1994.

9 Whelan T, Levine M, Julian J, Krikbridge P, Skingley P: The effects of radiation therapy in quality of life of women with breast cancer. Results of a randomized trial. Cancer 2000;88:2260-2266.

10 Yu CLM, Fielding R, Chan C, Tse V, Choi P, Lau W, Choy D, Lee AW, Sham JS: Measuring quality of life in chinese cancer patients 2000;88;1715-1727.

11 Stanton AL, Danoff-Burg S, Huggins ME: The first year after breast cancer diagnosis: Hope and coping strategies as predictors of adjustment. Psychooncology 2002;11:93-102.

12 Herschbach P, Henrich G: Probleme und Problembewältigung von Tumorpatienten in der stationären Nachsorge. Psychother Med Psychol 1987;37:185192

13 Cella DF, Tulsky DS, Gray G, B, Linn E, Bonomi A, Silberman M, Yellen SB, Winicour P, Brannon J: The Functional Assessment of Cancer Therapy scale: Development and validation of the general measure. J Clin Oncol 1993;11:570-579.

14 Norman D, Kordy H: Coping bei Morbus CrohnPatienten unter differentieller Perspektive. Ein Beitrag zur Spezifitätsdiskussion. Psychother Psychosom Med Psychol 1991;41:11-21.

15 Faller H, Lang H, Schilling S: Krankheitsverarbeitung bei Bronchialkarzinompatienten. Der Mehrebenenansatz; in: Krankheitsbewältigung bei Krebs und Möglichkeiten der Unterstützung. Stuttgart, Schattauer, 1992
16 Harrer ME, Mosheim R, Richter R, Walter MH, Kemmler G: Coping und Lebenszufriedenheit bei Patienten mit M. Hodgkin in Remission. Psychother Psychosom Med Psychol 1993;43:121-132.

17 Sherman AC, Simonton S, Adams DC, Vural E, Hanna E: Coping with head and neck cancer during different phrases of treatment. Head Neck 2000;22:787-793.

18 Petz T, Diete S, Gademann G, Wallesch CW: Coping in patients with malignant glioma in the course of radiation therapy. Psychother Psychosom Med Psychol 2001;51:281-287.

19 Brown J, Brown R, Miller R, Dunn S, King M, Coates A, Butow P: Coping with metastatic melanoma: The last year of life. Psychooncology 2000;9:283-292.

20 Stanton AL, Danoff-Burg S, Cameron C, Collins C, Sworowski L, Kirk S: A longitudinal study of emotional expression and adjustment to breast cancer. Paper presented at the 20th Annual Meeting of the Society of Behavioral Medicine, San Diego, CA, 1999

21 Heinonen H, Volin L, Uutela A, Zevon M, Barrick C, Ruutu T: Quality of life and factors related to perceived satisfaction with quality of life after allogenic bone marrow transplantation. Am Haematol 2001;80:137-143.

22 Higginson I, Wade A, McCarthy M: Palliative care: Views of patients and their families. BMJ 1990;301: 277-281. 
23 Sehlen S, Hollenhorst H, Lenk M, Schymura B, Aydemir U, Herschbach P, Dühmke E: Only sociodemographic variables predict quality of life (QoL) after radiotherapy in patients with head and neck cancer. Int J Radiat Oncol Biol Phys 2002;52:779783.

24 Sehlen S, Lenk M, Hollenhorst H, Schymura B, Aydemir U, Herschbach P, Dühmke E: Quality of life (QoL) as predictive mediator variable for survival in patients with intracerebral neoplasma during radiotherapy. Onkologie 2003;26:38-43.

25 Henrich G, Herschbach P: Objektive Bedingungen subjektiver Lebensqualität; in: Krankheitsbewältigung bei Krebs und Möglichkeiten der Unterstützung. Stuttgart, Schattauer, 1995.

26 Cotton SP, Levine EG, Fitzpatrick CM, Dold KH, Terg E: Exploring the relationships among spiritual well-being, quality of life and psychosocial adjustment in women with breast cancer. Psychooncology 1999;8:429-438.

27 Leeuw de JRJ, Graeff de A, Ros WJG, Hordijk GJ, Blijham GH, Winnubst JAM: Negative and positive influences of social support on depression in patients with head and neck cancer: A prospective study. Psychooncology 2000;9:20-28.

28 Heim E: Coping und Adaptivität: Gibt es geeignetes oder ungeeignetes Coping? Psychother Med Psychol 1988;38:8-18.

29 Sellick SM, Crooks DL: Depression and cancer: An appraisal of the literature for prevalence, detection and practice guideline development for psychological interventions. Psychooncology 1999;8:315-333.

30 Beutel M, Muthny FA: Konzeptionalisierung und klinische Erfassung von Krankheitsverarbeitung. Hintergrundtheorien, Methodenprobleme und künftige Möglichkeiten. Psychother Psychosom Med Psychol 1988;38:19-27.

31 Buddeberg K: Coping strategies in the course of disease of breast cancer- results of a three-year-longitudinal study. Psychother Psychosom 1991;55: 151-157.

32 Heim E, Augustiny KF, Blaser A, Kühne, D, Rothenbühler M, Schaffner L, Valach L: Stabilität und Variabilität von Copingstrukturen über die Zeit; in Muthny FA (Hrsg): Krankheitsverarbeitung, Hintergrundtheorien, klinische Erfassung und empirische Ergebnisse. Berlin, Springer, 1990, pp 88-106.

33 Trijsburg RW, van Knippenberg FC, Rijpma SE Effects of psychological treatment on cancer patients: A critical review. Psychosom Med 1992;54 489-517.

34 Schaffner L: Psychosoziale Interventionen bei Krebspatienten - eine Übersicht; in Heim E, Perrez M (Hrsg): Krankheitsverarbeitung. Göttingen, Hogrefe, 1994, pp 170-191.

35 Liu L, Meers K, Capurso A, Engebretson TO, Glicksman AS: The impact of radiation therapy on quality of life in patients with cancer. Cancer Pract 1998;6:237-242.

36 Soellner W, Maislinger S, DeVries A, Steixner E, Rumpold G, Lukas P: Use of Complementary and Alternative Medicine by Cancer Patients is not associated with perceived distress or poor compliance with standard treatment but with active coping behavior. Cancer 2000;89:873-880

37 Klee M, Thranov I, Machin D: Life after radiother apy: The psychosocial and social effects experienced by woman treated for advanced stages of cervical cancer. Gynecol Oncol 2000;76:5-13.

38 Sehlen S, Hollenhorst, H, Schymura B, Song R, Aydemir U, von Steinbuechel N, Duehmke E: Radiotherapy: Impact on quality of life and need for psychosocial care: Results of a longitudinal study. Onkologie 2000;23:565-570. 